\title{
The Effects of Inhaled Albuterol in Transient Tachypnea of the Newborn
}

\author{
Myo-Jing Kim, Jae-Ho Yoo, Jin-A Jung, ${ }^{1}$ Shin-Yun Byun²* \\ 'Department of Pediatrics, Dong-A University, College of Medicine, Busan, Korea \\ ${ }^{2}$ Department of Pediatrics, Pusan National University School of Medicine, Yangsan, Korea
}

This is an Open Access article distributed under the terms of the Creative Commons Attribution Non-Commercial License (http://creativecommons.org/licenses/by-nc/3.0/) which permits unrestricted non-commercial use, distribution, and reproduction in any medium, provided the original work is properly cited.

Purpose: Transient tachypnea of the newborn (TNN) is a disorder caused by the delayed clearance of fetal alveolar fluid. B-adrenergic agonists such as albuterol (salbutamol) are known to catalyze lung fluid absorption. This study examined whether inhalational salbutamol therapy could improve clinical symptoms in TTN. Additional endpoints included the diagnostic and therapeutic efficacy of salbutamol as well as its overall safety. Methods: From January 2010 through December 2010, we conducted a prospective study of 40 newborns hospitalized with TTN in the neonatal intensive care unit. Patients were given either inhalational salbutamol (28 patients) or placebo (12 patients), and clinical indices were compared. Results: The duration of tachypnea was shorter in patients receiving inhalational salbutamol therapy, although this difference was not statistically significant. The duration of supplemental oxygen therapy and the duration of empiric antibiotic treatment were significantly shorter in the salbutamol-treated group. No adverse effects were observed in either treatment group. Conclusions: Inhalational salbutamol therapy reduced the duration of supplemental oxygen therapy and the duration of empiric antibiotic treatment, with no adverse effects. However, the time between salbutamol therapy and clinical improvement was too long to allow definitive conclusions to be drawn. Further studies examining a larger number of patients with strict control over dosage and frequency of salbutamol inhalations are necessary to better direct the treatment of TTN.

Key Words: Transient tachypnea of the newborn; inhalation; albuterol

\section{INTRODUCTION}

Transient tachypnea of the newborn (TTN) is a respiratory disorder resulting from inadequate or delayed clearance of fetal lung fluid. ${ }^{1}$ It is commonly seen in full-term or late-preterm infants, ${ }^{2}$ with an occurrence rate of 5.7 in 1,000 infants. ${ }^{1}$ The disorder is more prevalent among infants who are male, premature, born via cesarean section without labor, or born to a mother with diabetes or asthma, and among infants who have perinatal asphyxia. ${ }^{3,4}$ Clinical symptoms include tachypnea, expiratory grunting, nasal flaring, and retraction upon or immediately after birth. These symptoms usually resolve naturally within 48-72 hours after birth, but can last up to 5 days. Treatment of TTN includes the administration of supplemental oxygen and postponement of enteral nutrition. ${ }^{1,4}$ The initial symptoms of TTN are not easily differentiated from those of neonatal respiratory distress syndrome, pneumonia, and persistent pulmonary hypertension of the newborn, leading to unnecessary imaging, blood testing, and empiric antibiotic therapy as a result of misdiagnoses.

Under normal circumstances, fetal lung fluid is rapidly cleared from the lungs shortly after birth. In this process, Sodium moves from the alveoli into pulmonary cells via the $\mathrm{Na}$, KATPase pump and is then actively transported to the interstitium via amiloride-sensitive epithelial Na channels, thereby removing Na and fluid through the lymphatic and vascular systems. ${ }^{1}$

Absorption of lung fluid is initiated by $\beta$-adrenergic agonists such as endogenous steroids and catecholamines, which increase during labor. ${ }^{5-7}$ Infants with TTN have lower levels of circulating catecholamines than those without TTN. Ex vivo stimulation of lung tissue with an exogenous $\beta$-adrenergic agonist has been shown to stimulate lung fluid absorption in both human and animal models. ${ }^{8-13}$ Additionally, recent in vivo and in vitro models for pulmonary edema suggest that intravenous injection of albuterol (salbutamol), a $\beta_{2}$-adrenergic agonist, stim-

Correspondence to: Shin-Yun Byun, MD, Department of Pediatrics, Busan National University Children's Hospital, 20 Geumo-ro, Yangsan 626-770, Korea. Tel: +82-51-240-5124; Fax: +82-51-242-2765; E-mail: neonate.kr@gmail.com Received: February 20, 2013; Revised: April 30, 2013; Accepted: June 3, 2013

- There are no financial or other issues that might lead to conflict of interest. 
ulates lung fluid absorption. ${ }^{14-16}$

In this context, we hypothesized that inhalational salbutamol, a $\beta_{2}$-adrenergic agonist widely used to treat bronchopulmonary dysplasia in premature infants, would stimulate lung fluid absorption in patients with TTN. The primary goal of this study was to examine the efficacy of inhalational salbutamol in reducing tachypnea, oxygen treatment, and hospitalization for infants with TTN. Our secondary goal was to assess the safety of inhalational salbutamol for the new indication of TTN.

\section{MATERIALS AND METHODS}

\section{Subjects}

We conducted a randomized, double-blind clinical trial of inhaled salbutamol for infants hospitalized with TTN in the neonatal intensive care unit of Dong-A Medical Center, Busan, Korea from January 2010 through December 2010. Infants with TTN were determined based on the following clinical symptoms and chest radiography results: 1) at least 35 weeks gestational age; 2) respiratory distress less than 6 hours after birth (i.e., respiratory rate greater than $60 / \mathrm{min}$, grunting, nasal flaring, or retraction); and 3) typical chest radiography findings (i.e., fluid in minor fissures, hyperinflation, prominent vascular/ perihilar markings). Patients were excluded if they exhibited any of the following: 1) meconium aspiration; 2) other causes of tachypnea (e.g., neonatal respiratory distress syndrome, persistent pulmonary hypertension of the newborn, pneumonia, early-onset neonatal sepsis, polycythemia, or hypoglycemia); 3) heart murmur; and 4) tachycardia (heart rate greater than 180/ min) or arrhythmia. Meconium aspiration syndrome was excluded when there were no abnormal chest radiography findings (irregular pattern of increased density throughout the lung) and no meconium staining of the skin. Respiratory distress syndrome was excluded when there were no reticulogranuler patterns on the chest radiograph and no surfactant therapy. Persistent pulmonary hypertension of the newborn was excluded when the level of preductal oxygen saturation was $<5 \%$ above postductal oxygen saturation. Sepsis was excluded when there were no perinatal risk factors, WBC $>5,000 / \mathrm{mm}^{3}{ }^{3} \mathrm{imma}-$ ture-to-total neutrophil (I:T) ratio $<0.25$, negative C-reactive protein, and no focal infiltration on chest radiography. Oxygen was supplemented to maintain oxygen saturation at $90 \%-95 \%$. Empirical antibiotic therapy was considered prior to culture results when there was no clinical improvement despite oxygen supplementation and supportive care.

\section{Study design}

Infants were randomly allocated in a double-blind fashion to receive 1 dose of $2 \mathrm{~mL}$ nebulized $0.9 \%$ normal saline (placebo) or $0.1 \mathrm{~mL}$ salbutamol (Ventolin Respiratory Solution, salbutamol sulfate $5 \mathrm{mg} / \mathrm{mL}$; GlaxoSmithKline Inc., UK) in $2 \mathrm{~mL}$ of $0.9 \%$ normal saline. The standard dose of salbutamol was 0.15 $\mathrm{mg} / \mathrm{kg}$. Each dose was nebulized with a jet-type nebulizer (PariBoy $^{\circledR}$, Pari-Werk, Stanberg, Germany) with continuous flow of oxygen at $5 \mathrm{~L} / \mathrm{min}$ and was administered over the course of 10 minutes. During the hospitalization period, the respiratory rate, heart rate, and oxygen saturation level of each patient were observed. The target oxygen saturation level was between $90 \%$ and $95 \%$. Tachypnea was defined as a respiratory rate $>60$ breaths/min; and tachycardia, as a heart rate $>180$ beats $/ \mathrm{min}$. We agreed to stop treatment if any patient were to develop tachycardia or an arrhythmia. Supportive treatment began after the inhalational treatment was complete.

To assess the efficacy of salbutamol for TTN, we investigated the extent and duration of tachypnea, the duration of oxygen treatment, the use of continuous positive airway pressure or a ventilator, the duration of empiric antibiotic therapy, the time of initiating enteral nutrition, and the duration of hospitalization. To assess the safety of salbutamol, we monitored for tachycardia and arrhythmias.

\section{Statistics}

SPSS 18.0 for Windows (SPSS Inc., Chicago, IL, USA) was used for all analyses. Values are shown as averages \pm standard deviation. Two-tailed tests were used for all statistical tests, with statistical significance defined as $P \leq 0.05$. To compare the frequency and proportion of categorical variables, a Chi-squared test (Fisher's exact test) was used. Student's $t$-test was used to analyze differences between the averages of 2 independent groups.

\section{Ethics statement}

The study was approved by the Institutional Review Board of the Dong-A Medical Center, Busan, Korea (IRB No. 11-36). Informed consent was confirmed by the IRB. Consent was received from the mother or the infant's legal representative at the time of hospital admission.

\section{RESULTS}

\section{Characteristics of study patients}

A total of 40 infants were included in this study: 28 patients were randomized into the treatment group (salbutamol inhalation); and 12, into the control group (saline inhalation). The average gestational age of all patients was $37.6 \pm 1.0$ weeks, and the birth weight was $3,124 \pm 545 \mathrm{~g}$. Twenty-four of the subjects were male $(60.0 \%)$. Twenty-nine infants were born via C-section (72.5\%), of which 26 were born without labor (65.0\%). The average Apgar score was $7.8 \pm 1.2$ at 1 minute and $9.0 \pm 0.8$ at 5 minute. On average, neonatal tachypnea was first detected 1.3 \pm 2.1 hours after birth, and the initial respiration rate was $74 \pm$ $12.8 \mathrm{breaths} / \mathrm{min}$. There were no significant differences between the treatment and control groups with regard to any of the following: gestational age $(37.6 \pm 1.9$ weeks vs $37.5 \pm 1.0$ 
weeks), birth weight (3,090.7 \pm 591 g vs 3,203.3 \pm 432.4 g), delivery method (vaginal delivery vs cesarean section), 1-min Apgar score, 5-min Apgar score, time of tachypnea onset, initial respiration rate, oxygen saturation upon hospitalization, blood gas test results, empiric use of antibiotics, and medical history of mother (Table 1).

\section{Effect of salbutamol treatment on tachypnea (primary outcome)}

The initial respiration rates were similar between the study and control groups $(73.3 \pm 12.5$ breaths/min and $75.8 \pm 14.0$ breaths/ min, respectively). The duration of tachypnea after treatment was shorter in the treatment group than in the control group (31.3 \pm 23.7 hours vs $53.5 \pm 56.8$ hours, respectively); however, this difference was not significant $(P=0.37)$. The duration of oxygen treatment was significantly shorter in the treatment group (34.2 \pm 32.2 hours) than in the control group $(77.3 \pm 64.7$ hours $(P<0.01)$.

The use of empiric antibiotic therapy did not differ between the 2 groups, although the duration of empiric antibiotic use was significantly shorter in the treatment group (1.5 \pm 1.6 days vs $3.4 \pm 3.0$ days; $P=0.04$ ) (Table 2). The time before initiating enteral nutrition was also shorter in the treatment group ( $12.1 \pm 19.8$ hours vs $28.5 \pm 45$ hours), suggesting that the treat-

Table 1. Demographics of the Study Population

\begin{tabular}{|c|c|c|c|}
\hline Variable & $\begin{array}{c}\text { Treatment group, } \\
n=28\end{array}$ & $\begin{array}{c}\text { Control group, } \\
n=12\end{array}$ & $P$ \\
\hline Gestational age, weeks & $37+6 \pm 1.9$ & $37+5 \pm 1.0$ & 0.80 \\
\hline Birth weight (g) & $3,090.7 \pm 591$ & $3,203.3 \pm 432$ & 0.56 \\
\hline Male (\%) & $17(60.7)$ & $7(58.3)$ & 0.58 \\
\hline \multicolumn{4}{|l|}{ Delivery method } \\
\hline Vaginal (\%) & $9(32.1)$ & $2(16.7)$ & \\
\hline Elective cesarean (\%) & $17(60.7)$ & $9(75)$ & 0.31 \\
\hline Emergency cesarean (\%) & $2(7.1)$ & $1(8.3)$ & \\
\hline AS1 & $7.8 \pm 1.3$ & $7.8 \pm 1.0$ & 0.91 \\
\hline AS5 & $9.0 \pm 1.0$ & $9.0 \pm 0.5$ & 0.89 \\
\hline Without labor (\%) & $17(60.7)$ & $9(75.0)$ & 0.31 \\
\hline Maternal asthma (\%) & $0(0)$ & $1(8.3)$ & 0.30 \\
\hline Maternal DM (\%) & $1(3.6)$ & $0(0)$ & 0.70 \\
\hline Maternal PIH (\%) & $2(7.1)$ & $0(0)$ & 0.49 \\
\hline Maternal BB (\%) & $0(0)$ & $0(0)$ & \\
\hline Maternal pneumonia (\%) & $0(0)$ & $0(0)$ & \\
\hline Onset of tachypnea (h) & $1.6 \pm 2.4$ & $0.6 \pm 1.1$ & 0.09 \\
\hline Initial RR (breaths/min) & $73.3 \pm 12.5$ & $75.8 \pm 14.0$ & 0.58 \\
\hline Oxygen (\%) & $25(89.3)$ & $12(100)$ & 0.33 \\
\hline Antibiotics (\%) & $16(57.1)$ & $9(75.0)$ & 0.24 \\
\hline $\mathrm{pH}$ & $7.34 \pm 0.08$ & $7.36 \pm 0.04$ & 0.41 \\
\hline $\mathrm{SpO}_{2}$ & $94.4 \pm 4.5$ & $93.1 \pm 6.0$ & 0.45 \\
\hline
\end{tabular}

Values are presented as n (\%) or average \pm SD. AS1, Apgar score at 1 min; AS5, Apgar score at 5 min; DM, diabetes mellitus; $\mathrm{PHH}$, pregnancy-induced hypertension; $\mathrm{BB}$, beta blocker; $\mathrm{RR}$, respiration rate ment group was able to begin enteral nutrition earlier; however, this difference did not reach statistical significance $(P=0.31)$. The duration of hospitalization was similar between the 2 groups (8.5 \pm 3.9 days vs $8.8 \pm 3.2$ days, treatment group vs control group).

A comparison of maximum respiratory rates per minute showed no differences in the 6 hours immediately following treatment. In the salbutamol treatment group, maximal respiration rates gradually decreased over the course of 72 hours (Figure), reaching statistical significance at 72 hours (43 breaths/ min vs 57 breaths/min, treatment group vs control group; $P=0.04$ ) (Figure).

Table 2. Clinical Course

\begin{tabular}{lccc}
\hline Variable & Treatment group, $\mathrm{n}=28$ & Control group, $\mathrm{n}=12$ & $P$ \\
\hline $\begin{array}{c}\text { Period of } \\
\text { tachypnea (h) }\end{array}$ & $31.3 \pm 23.7$ & $53.5 \pm 56.8$ & 0.37 \\
$\begin{array}{c}\text { Oxygen duration } \\
\text { (h) }\end{array}$ & $34.2 \pm 32.2(\mathrm{n}=25)$ & $77.3 \pm 64.7(\mathrm{n}=12)$ & $<0.01$ \\
$\begin{array}{c}\text { Antibiotics } \\
\text { duration (day) }\end{array}$ & $1.5 \pm 1.6(\mathrm{n}=16)$ & $3.4 \pm 3.0(\mathrm{n}=9)$ & 0.04 \\
$\begin{array}{c}\text { Start enteral } \\
\text { feeding (h) }\end{array}$ & $12.1 \pm 19.9$ & $28.5 \pm 45.9$ & 0.31 \\
$\begin{array}{l}\text { Hospital duration } \\
\text { (day) }\end{array}$ & $8.5 \pm 3.9$ & $8.8 \pm 3.2$ & 0.58 \\
Tachycardia (n) & 0 & 0 & \\
Arrhythmias $(\mathrm{n})$ & 0 & 0 &
\end{tabular}

Tachypnea, as a respiratory rate $>60$ breaths/min; Tachycardia, as a heart rate $>180$ beats/min.
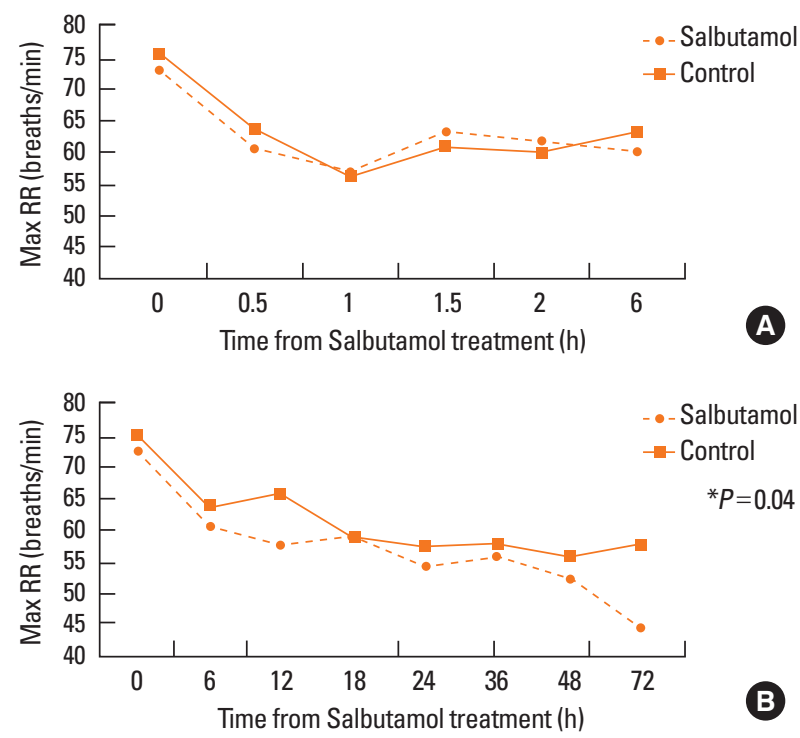

Figure. No differences in the maximum respiratory rates during the acute period after inhalation treatment were observed between the salbutamol inhalation group and the control group (A). A trend toward lower maximal respiratory rates was evident in the treatment group at later time points (B). RR, respiratory rate. 


\section{Reliability of inhaled salbutamol (secondary outcome)}

The predicted side effects of inhaled salbutamol were tachycardia (heart rate $>180$ beats/min) and arrhythmias. No such effects were reported for either the treatment or control group (Table 2) in this study.

\section{DISCUSSION}

As many as $1 \%$ of all newborns experience some form of respiratory distress. Among newborns hospitalized due to respiratory distress, one-third are ultimately diagnosed as having TTN, particularly those admitted to the neonatal intensive care unit. ${ }^{18,19}$ Although the exact pathology of the condition remains poorly understood, it is most commonly associated with delayed absorption of fetal alveolar fluid after birth. ${ }^{1,17}$ During pregnancy, some lung fluid is required for normal growth and development of the lungs. Starting 2-3 days before birth, fluid begins to drain from the lungs, thereby aiding the transition to the ex utero environment. As labor begins, the pulmonary epithelium changes from a chloride-secreting membrane to a sodium-absorbing membrane, thus reversing the flow of lung fluid. When this occurs, Na begins to move from the alveoli into pulmonary cells via the $\mathrm{Na}$, K-ATPase pump and is then actively transported into the interstitium via amiloride-sensitive epithelial Na channels, bringing with it alveolar fluid. ${ }^{20}$ This process can be stimulated by the addition of an exogenous $\beta$-adrenergic agonist, leading to fluid absorption in the lungs. ${ }^{8,9}$ In vivo models of pulmonary edema using $\beta_{1}$ - and $\beta_{2}$-receptor knockout mice have shown this process to be driven primarily by $\beta_{2}$-receptors, ${ }^{10}$ which is consistent with recent work showing that intravenous injection of salbutamol, a $\beta_{2}$-adrenergic agonist, catalyzes lung fluid absorption. ${ }^{14,15}$

Considering these findings, we hypothesized that salbutamol would stimulate lung fluid absorption in infants with TTN. TTN is characterized by relatively mild symptoms that resolve naturally over time; therefore, the potential risk associated with systemic salbutamol therapy was not warranted. Inhalational formulations of salbutamol should effectively reach the lung while minimizing systemic effects. Furthermore, the safety and efficacy of this approach are well documented, as this method is commonly used to treat bronchopulmonary dysplasia in premature infants.

The primary goal of our study was to observe the effects of inhalational salbutamol on the clinical symptoms of infants with TTN. To this end, we examined the duration of tachypnea, oxygen treatment, and hospitalization. No differences were observed between the treatment and control groups with regard to birth history or maternal medical history events that could have influenced the clinical symptoms. There were no significant differences in the time of tachypnea onset, initial respiration rate, oxygen saturation upon hospitalization, blood gas results, and empiric use of antibiotics between the 2 groups.
However, infants receiving salbutamol inhalation therapy showed a shorter duration of tachypnea compared with the control group. This led to shorter durations of oxygen treatment and empiric antibiotic treatment in the salbutamol inhalation group.

To further evaluate the efficacy of salbutamol treatment, we examined the change in post-inhalational maximum breathing rate over time. No difference was observed between the 2 groups, nor was the duration of hospitalization reduced. $\mathrm{Al}$ though no differences in maximum respiration rates were seen during the acute period, a clear trend toward lower maximal respiratory rates was seen in the treatment group at later time points. These findings suggest that salbutamol inhalational therapy may be useful for the treatment of prolonged tachypnea of the newborn. ${ }^{19}$

None of the infants developed tachycardia or arrhythmias from the inhaled salbutamol treatment, consistent with what is seen in the treatment of bronchopulmonary dysplasia. Salbutamol inhalation is therefore believed to be a low-risk treatment for TTN patients.

TTN tends to resolve spontaneously, and thus immediate and dramatic improvement in clinical indices directly after inhalation would be needed to support salbutamol for diagnosis and therapy. In our study, the duration of tachypnea tended to be shorter for patients treated with salbutamol versus those in the control group. The duration of supplemental oxygen therapy and empiric antibiotic treatment was also significantly shorter in the treatment group. However, a change in clinical indices immediately after salbutamol inhalation treatment was not observed.

This work represents the first Korean study investigating salbutamol inhalational treatment for infants with TTN. Specific limitations of this study include the small number of subjects and the lack of control over the dose and frequency of salbutamol inhalation. Further research is needed to examine the effects of inhaled salbutamol on TTN in a larger number of infants. Greater control over the dosage and frequency of salbutamol inhalation are also necessary to fully characterize the effect of this treatment on TTN.

\section{ACKNOWLEDGMENTS}

This study was supported by the Dong-A University Research Fund.

\section{REFERENCES}

1. Abu-Shaweesh JM. Respiratory disorders in preterm and term infants. In: Martin RJ, Fanaroff AA, Walsh MC, editors. Fanaroff and Martin's neonatal-perinatal medicine: diseases of the fetus and infant. 9th ed. St. Louis (MO): Elsevier Mosby; 2010. 1162-63.

2. Clark RH. The epidemiology of respiratory failure in neonates born at an estimated gestational age of 34 weeks or more. J Perinatol 
2005;25:251-7.

3. Takaya A, Igarashi M, Nakajima M, Miyake H, Shima Y, Suzuki S. Risk factors for transient tachypnea of the newborn in infants delivered vaginally at 37 weeks or later. J Nippon Med Sch 2008; 75:269-73.

4. Lewis V, Whitelaw A. Furosemide for transient tachypnea of the newborn. Cochrane Database Syst Rev 2002;(1):CD003064.

5. Jain L, Eaton DC. Physiology of fetal lung fluid clearance and the effect of labor. Semin Perinatol 2006;30:34-43.

6. Richardson BS, Czikk MJ, daSilva O, Natale R. The impact of labor at term on measures of neonatal outcome. Am J Obstet Gynecol 2005; 192:219-26.

7. Zanardo V, Simbi AK, Franzoi M, Soldà G, Salvadori A, Trevisanuto D. Neonatal respiratory morbidity risk and mode of delivery at term: influence of timing of elective caesarean delivery. Acta Paediatr 2004;93:643-7.

8. Sakuma T, Tuchihara C, Ishigaki M, Osanai K, Nambu Y, Toga H, Takahashi K, Ohya N, Kurihara T, Matthay MA. Denopamine, a beta(1)-adrenergic agonist, increases alveolar fluid clearance in ex vivo rat and guinea pig lungs. J Appl Physiol 2001;90:10-6.

9. Sakuma T, Folkesson HG, Suzuki S, Okaniwa G, Fujimura S, Matthay MA. Beta-adrenergic agonist stimulated alveolar fluid clearance in ex vivo human and rat lungs. Am J Respir Crit Care Med 1997;155:506-12.

10. Mutlu GM, Factor P. Alveolar epithelial beta2-adrenergic receptors. Am J Respir Cell Mol Biol 2008;38:127-34.

11. Irestedt L, Lagercrantz H, Hjemdahl P, Hägnevik K, Belfrage P. Fetal and maternal plasma catecholamine levels at elective cesarean section under general or epidural anesthesia versus vaginal delivery. Am J Obstet Gynecol 1982;142:1004-10.
12. Ronca AE, Abel RA, Ronan PJ, Renner KJ, Alberts JR. Effects of labor contractions on catecholamine release and breathing frequency in newborn rats. Behav Neurosci 2006;120:1308-14.

13. Smith DE, Otulakowski G, Yeger H, Post M, Cutz E, O'Brodovich $\mathrm{HM}$. Epithelial $\mathrm{Na}(+)$ channel (ENaC) expression in the developing normal and abnormal human perinatal lung. Am J Respir Crit Care Med 2000;161:1322-31.

14. Perkins GD, Gao F, Thickett DR. In vivo and in vitro effects of salbutamol on alveolar epithelial repair in acute lung injury. Thorax 2008;63:215-20.

15. Perkins GD, McAuley DF, Richter A, Thickett DR, Gao F. Bench-tobedside review: beta2-Agonists and the acute respiratory distress syndrome. Crit Care 2004;8:25-32.

16. Mutlu GM, Dumasius V, Burhop J, McShane PJ, Meng FJ, Welch L, Dumasius A, Mohebahmadi N, Thakuria G, Hardiman K, Matalon S, Hollenberg S, Factor P. Upregulation of alveolar epithelial active $\mathrm{Na}+$ transport is dependent on beta2-adrenergic receptor signaling. Circ Res 2004;94:1091-100.

17. Welty S, Hansen TN, Corbet A. Respiratory distress in the preterm infant. In: Taeusch HW, Ballard RA, Gleason CA, Avery ME, editors. Avery's diseases of the newborn. 8th ed. Philadelphia (PA): Elsevior Saunders; 2005. 697-9.

18. Karabayir N. Intravenous furosemide therapy in transient tachypnea of the newborn. Pediatr Int 2010;52:851.

19. Kasap B, Duman N, Ozer E, Tatli M, Kumral A, Ozkan H. Transient tachypnea of the newborn: predictive factor for prolonged tachypnea. Pediatr Int 2008;50:81-4.

20. Fukuda N, Folkesson HG, Matthay MA. Relationship of interstitial fluid volume to alveolar fluid clearance in mice: ventilated vs in situ studies. J Appl Physiol 2000;89:672-9. 